\title{
GSKIP-Mediated Anchoring Increases Phosphorylation of Tau by PKA but Not by GSK3beta via cAMP/PKA/GSKIP/GSK3/Tau Axis Signaling in Cerebrospinal Fluid and iPS Cells in Alzheimer Disease
}

\author{
Huey-Jiun Ko ${ }^{1,2, \dagger}$, Shean-Jaw Chiou ${ }^{1,2,3, \dagger}$, Yu-Hui Wong ${ }^{4,+} \mathbb{D}$, Yin-Hsuan Wang ${ }^{1,2}$, \\ Yun-Ling Lai ${ }^{1,2}$, Chia-Hua Chou ${ }^{1,2}$, Chihuei Wang ${ }^{5}$, Joon-Khim Loh ${ }^{1,6}$, Ann-Shung Lieu 1,6, \\ Jiin-Tsuey Cheng ${ }^{7}$, Yu-Te Lin ${ }^{8}$, Pei-Jung Lu ${ }^{9}$, Ming-Ji Fann ${ }^{10}$, Chi-Ying Huang $2,11, *(\mathbb{D}$ and \\ Yi-Ren Hong ${ }^{1,2,3,7, *}$ \\ 1 Graduate Institute of Medicine, College of Medicine, Kaohsiung Medical University, Kaohsiung 807, Taiwan; \\ o870391@yahoo.com.tw (H.-J.K.); sheanjaw@kmu.edu.tw (S.-J.C.); kime036@gmail.com (Y.-H.W.); \\ 4a1h0010@gmail.com (Y.-L.L.); lucifer0408@hotmail.com (C.-H.C.); jokhlo@kmu.edu.tw (J.-K.L.); \\ e791125@gmail.com (A.-S.L.) \\ 2 Department of Biochemistry, Kaohsiung Medical University, Kaohsiung 807, Taiwan \\ 3 Department of Medical Research, Kaohsiung Medical University Hospital, Kaohsiung 807, Taiwan \\ 4 Brain Research Center, National Yang-Ming University, Taipei 11221, Taiwan; yuhui.wong@gmail.com \\ 5 Department of Biotechnology, Kaohsiung Medical University, Kaohsiung 807, Taiwan; chwang@kmu.edu.tw \\ 6 Department of Neurosurgery, Kaohsiung Medical University Hospital, Kaohsiung 807, Taiwan \\ 7 Department of Biological Sciences, National Sun Yat-Sen University, Kaohsiung 804, Taiwan; \\ tusya@mail.nsysu.edu.tw \\ 8 Section of Neurology, Kaohsiung Veterans General Hospital, Kaohsiung 813, Taiwan; ytlin@vghks.gov.tw \\ 9 Institute of Clinical Medicine, School of Medicine, National Cheng Kung University, Tainan 701, Taiwan; \\ pjlu2190@mail.ncku.edu.tw \\ 10 Department of Life Sciences and Institute of Genome Sciences and Brain Research Center, National \\ Yang-Ming University, Taipei 11221, Taiwan; mjfann@ym.edu.tw \\ 11 Institute of Biopharmaceutical Sciences, National Yang-Ming University, Taipei, Taiwan; Department of \\ Biotechnology and Laboratory Science in Medicine, National Yang-Ming University, Taipei 112, Taiwan \\ * $\quad$ Correspondence: cyhuang5@ym.edu.tw (C.-Y.H.); m835016@kmu.edu.tw (Y.-R.H.) \\ + These authors contributed equally.
}

Received: 1 October 2019; Accepted: 17 October 2019; Published: 21 October 2019

check for updates

\begin{abstract}
Based on the protein kinase A (PKA)/GSK3 $\beta$ interaction protein (GSKIP)/glycogen synthase kinase $3 \beta$ (GSK3 $\beta$ ) axis, we hypothesized that these might play a role in Tau phosphorylation. Here, we report that the phosphorylation of Tau Ser409 in SHSY5Y cells was increased by overexpression of GSKIP WT more than by PKA- and GSK3 $\beta$-binding defective mutants (V41/L45 and L130, respectively). We conducted in vitro assays of various kinase combinations to show that a combination of GSK3 $\beta$ with PKA but not $\mathrm{Ca}^{2+} /$ calmodulin-dependent protein kinase II (CaMK II) might provide a conformational shelter to harbor Tau Ser409. Cerebrospinal fluid (CSF) was evaluated to extend the clinical significance of Tau phosphorylation status in Alzheimer's disease (AD), neurological disorders (NAD), and mild cognitive impairment (MCI). We found higher levels of different PKA-Tau phosphorylation sites (Ser214, Ser262, and Ser409) in AD than in NAD, MCI, and normal groups. Moreover, we used the CRISPR/Cas9 system to produce amyloid precursor protein $\left(A P P^{\mathrm{WT} / \mathrm{D} 678 \mathrm{H}}\right)$ isogenic mutants. These results demonstrated an enhanced level of phosphorylation by PKA but not by the control. This study is the first to demonstrate a transient increase in phosphor-Tau caused by PKA, but not GSK3 $\beta$, in the CSF and induced pluripotent stem cells (iPSCs) of AD, implying that both GSKIP and GSK3 $\beta$ function as anchoring proteins to strengthen the $\mathrm{CAMP} / \mathrm{PKA} / \mathrm{Tau}$ axis signaling during AD pathogenesis.
\end{abstract}


Keywords: PKA/GSKIP/GSK3ß/Tau axis; SH-SY5Y; iPS cells; cerebrospinal fluid; Alzheimer's disease

\section{Introduction}

GSK3 $\beta$ interaction protein (GSKIP) is the smallest A-kinase anchor protein (AKAP) [1,2]. It functions as a cytosolic scaffolding protein that can bind protein kinase A (PKA) and glycogen synthase kinase $3 \beta$ (GSK3 $\beta$ ). GSKIP retains the PKA RII binding sites at residue V41/L45 and the GSK3 $\beta$ binding domain at residue L130 [1-6]. The latter is known to act synergistically with cAMP/PKA signaling to inhibit GSK3 $\beta$ activity $[1,7]$. GSKIP that directly interacts with GSK3 $\beta$ and negatively regulates GSK3 $\beta$ signaling is required for negative Wnt signaling regulation via a cytoplasmic destruction complex that targets $\beta$-catenin for degradation $[5,6,8,9]$. GSKIP can compete for GSK3 $\beta$ binding, resulting in control of the $\beta$-catenin stabilizing phosphorylation at Ser675 by PKA [9]. Its interaction with GSK3 $\beta$ facilitates control of the phosphorylation at Ser-33/37/Thr-41, which destabilizes $\beta$-catenin. The effect of GSKIP on $\beta$-catenin may be as a scavenger because it recruits GSK3 $\beta$ away from the destruction complex without forming a complex with $\beta$-catenin [8]. According to our previous findings, GSK3 $\beta$ binding of GSKIP is involved in the control of neurite outgrowths in the neuronal-like SH-SY5Y cell line, suggesting a role in neural development [5]. Furthermore, because of the dual binding sites of GSKIP, we previously proposed that GSKIP and GSK3 $\beta$ form a complex and likely act as anchoring proteins in the $\mathrm{CAMP} / \mathrm{PKA} / \mathrm{Drp} 1$ signaling axis to modulate Drp1 phosphorylation, which may provide neuroprotection against $\mathrm{H}_{2} \mathrm{O}_{2}$-induced oxidative stress in the neuron-like SH-SY5Y cell line [7]. Loss of GSKIP expression results in embryonic lethality attributable to a developmental defect in palatal shelf fusion, as determined through knockout animal models [10]. GSKIP has been characterized as one of the predisposing genes of familial myeloproliferative neoplasms in gene overexpression studies [11,12]. More recently, the loss of the peroxisome proliferator-activated receptor gamma-E2F1 (PPAR $\gamma$-E2F1) axis in the lungs was found to lead to a deficient complex with Wnt signaling that caused downregulation of GSKIP and eventually resulted in decreased angiogenesis, indicating that GSKIP may be involved in PPAR $\gamma$-related angiogenic potential in mature pulmonary microvascular endothelial cells (PMVECs) through E2F1 [13]. Collectively, these findings prompt us to believe that GSKIP has a role in neurodevelopment. However, the PKA/GSKIP/GSK3 $\beta$ axis and the PKA and GSK3 signaling pathways involved in the pathogenesis of neurodegenerative disease events remain unclear. Clarifying the roles of these would help advance drug development for neuron-related disorders such as Alzheimer's disease (AD).

$\mathrm{AD}$ is a neurodegenerative disorder and the main form of dementia, accounting for up to $60-70 \%$ of dementia cases; its prevalence is highly associated with advanced age [14]. The worldwide prevalence of AD was 33 million patients in 2018. By 2050, an estimated 107 million individuals worldwide will be living with the disease [15]. The characteristic neuropathological changes that are found in patients with $\mathrm{AD}$ are the presence of extracellular amyloid- $\beta(\mathrm{A} \beta)$ deposition and the formation of intracellular neurofibrillary tangles (NFTs) [16]. Tau is a normal, unfolded, highly soluble protein that plays a critical role in tubulin assembly and stabilization of microtubules, thereby promoting normal function and axonal localization of neurons, and its hyperphosphorylation plays a key role in the pathogenesis of $\mathrm{AD}$; Tau undergoes conformational changes in which the conversion of Tau monomer to Tau oligomer induces the aggregation of Tau into a paired helical filament, leading to the formation of NFTs in $\mathrm{AD}$ [17]. Several studies have focused on the A $\beta$-targeting pathology as a potential treatment for $\mathrm{AD}$; however, clinical evidence has shown that antiamyloid treatment for AD has not been effective at slowing the progression of the disease. Because tauopathies are indicated in dementia and AD, attention has shifted toward researching the pathology of Tau proteins and the mechanisms involved as well as potential Tau-targeted therapies for AD. More recently, 3D pharmacophore drug discovery methods and molecular docking have been applied to discover potent phosphor-Tau inhibitors in AD [18]. 
Anomalous signal transduction is related to the causes of neurodegenerative diseases. According to in vitro and in vivo evidence concerning neurodegenerative diseases such as $A D, G S K 3 \beta$ has a crucial role in memory impairment [19]. AD has been highly associated with GSK3 $\beta$ hyperactivity in advanced studies [19-21]. Notably, GSK3 $\beta$ phosphorylates Tau to reduce microtubule binding ability, and this results in microtubule destabilization that further leads to accumulation of $A \beta$ peptides [21,22]. Another cause of the accumulation of $A \beta$ and $\beta$-amyloid plaques is anomalous amyloid precursor protein $(A P P)$ metabolism that also leads to AD. There are multiple structures of $\mathrm{A} \beta$ peptide; one is $\mathrm{A} \beta$ 40 , which exists mainly in cerebrospinal fluid (CSF), and another is $A \beta 42$, which is associated with the formation of $\beta$-amyloid plaques $[16,23]$. A $\beta$ formation promotes the hyperactivity of GSK3 $\beta$ in abnormal-APP-metabolism induced pluripotent stem cells (iPSCs) and in animal models [19,24-26]. In recent years, we have focused on the effects of the regulatory mechanism of GSK $3 \beta$ and its binding proteins on neuron degeneration disease, especially GSKIP, which suppresses GSK3 $\beta$ activity and Tau phosphorylation $[5,6]$.

We have revealed that PKA enzyme activity is required for the formation of a complex comprising PKA/GSKIP/GSK3 $\beta$ that influences the phosphorylation of dynamin related protein 1 (Drp1) at Ser637 and $\beta$-catenin at Ser675 [7,9]. Recently, Ser409 phosphorylation of Tau-a known PKA/GSK3 $\beta$ substrate-was revealed to be associated with the termination of neurons in $\mathrm{AD}$ [27]. In the present study, we sought to use the PKA/GSKIP/GSK3 $\beta$ axis as a platform on which to search for a novel pathway that regulates through both PKA and GSK3 $\beta$ and then use it to investigate the mechanism underlying neuron protection or degeneration. In addition, we studied the spatiotemporal characteristics of Tau phosphorylation via the cAMP/PKA/Tau axis complex to determine the mechanism of Tau in AD. Our data reveal that both GSKIP and GSK3 $\beta$ function as anchoring proteins that are involved in

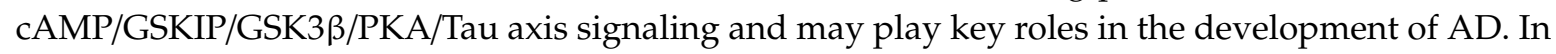
particular, data suggest the feasibility of determining a standard criterion whereby AD can be detected by examining total Tau alone with PKA phosphor-Tau sites (Ser214, Ser262, and Ser409) in CSF and the transient increase in phosphor-Tau by PKA but not GSK3 $\beta$ in CSF or iPSCs. Phosphor-Tau anchored by GSKIP via PKA sites could act as novel diagnostic and therapeutic means to protect against different types of $\mathrm{AD}$ in personalized medicine.

\section{Materials and Methods}

\subsection{Cell Culture}

The human neuroblastoma SH-SY5Y and human renal epithelial (HEK293) cell lines (American Type Culture Collection, Manassas, VA, USA) were used for these experiments.

SH-SY5Y cells were cultured in Dulbecco's modified Eagle's medium (DMEM)/F12, and HEK293 cells were cultured in DMEM (GIBCO BRL Life Technologies, Invitrogen Life Technologies, Carlsbad, CA, USA) containing $10 \%$ fetal bovine serum, penicillin $(100 \mathrm{U} / \mathrm{mL})$, and streptomycin $(100 \mu \mathrm{g} / \mathrm{mL}$; Invitrogen Life Technologies, Carlsbad, CA, USA). Cells were maintained in $5 \% \mathrm{CO}_{2}$ at $37^{\circ} \mathrm{C}$ and were passaged every $72 \mathrm{~h}$.

\subsection{Transfection and RNA Interference}

For transient transfections, SH-SY5Y and HEK293 cells were seeded onto glass coverslips at a density of $1 \times 10^{5}$ cells using a 6 -well plate $24 \mathrm{~h}$ prior to transfection. The following were transfected into the cells using Lipofectamine 3000 (Invitrogen Life Technologies, Carlsbad, CA, USA) according to the manufacturer's instructions: pEGFP-C1, pEGFP-C1-GSKIP, pEGFP-C1-GSKIP (L130P), pEGFP-C1-GSKIP (V41/L45P) pEGFP-C1-Tau, pET32a-HA, pET32a-HA-GSKIP, pET32a-HA-GSKIP (L130P), pET32a-HA-GSKIP (V41/L45P), pET32a-HA-GSK3 $\beta$, pET32a-HA-GSK3 $\beta$ (K85R), and pET32a-HA-GSK3 $\beta$ (K85M) plasmid DNA $(2 \mu \mathrm{g})$. After a $24 \mathrm{~h}$ transfection, the cells were cultured in fresh medium and further assayed. Three of GSK3 $\beta$ siRNA and scrambled siRNA duplexes were used for RNA interference assays. For the siRNA-mediated knockdown of GSKIP expression, approximately 
$1 \times 10^{5}$ or $1 \times 10^{6}$ cells were plated onto 12 -well plates or $100 \mathrm{~mm}$ dishes and left to grow overnight. The following day, cells were transfected with the siRNA duplex (final concentration, $50 \mathrm{nM}$ ) using Lipofectamine 3000 (Invitrogen Life Technologies, Carlsbad, CA, USA).

\subsection{Cloning and DNA Sequencing}

To construct pET32a-HA-GSK3 $\beta$, pET32a-HA-GSKIP and pEGFP-C1-GSKIP plasmids were constructed separately by inserting PCR fragments into commercial HA or EGFP expression vectors.

GSKIP L130P (Leu 130 to Pro), V41/L45P (Val 41 and Leu 45 to Pro), GSK3 $\beta$ K85R (Lys 85 to Arg), and K85M (Lys 85 to Met) mutants were created using the site-directed mutagenesis technique with a QuikChange Lightning Site-Directed Mutagenesis kit (GE Healthcare, Sunnyvale, CA, USA). All experimental procedures were carried out following the manufacturer's protocol, and mutated nucleotides were verified by DNA sequencing with an ABI PRISM 3730 Genetic Analyzer (Applied Biosystems, Forster City, CA, USA).

\subsection{In Vitro Kinase Assay}

In vitro kinase reactions were performed by mixing $1 \mu \mathrm{g}$ of the recombinant active GSK3 $\beta$, PKA, and $\mathrm{Ca}^{2+} /$ calmodulin-dependent protein kinase II (CaMK II) (New England Biolabs, BioLabs, Ipswich, MA, USA), all of which were incubated at room temperature for $30 \mathrm{~min}$ under a reaction condition that entailed $20 \mu \mathrm{L}$ of the kinase activity buffer $(50 \mathrm{mM}$ Tris $\mathrm{HCl}, 10 \mathrm{mM} \mathrm{MgCl}, 1 \mathrm{mM}$ dithiothreitol, $10 \mu \mathrm{M}$ ATP, $\mathrm{pH}$ 7.5); the reaction was subsequently stopped by adding $10 \mu \mathrm{L}$ of SDS-PAGE loading buffer. After denaturation at $95^{\circ} \mathrm{C}$ for $1 \mathrm{~min}$, protein phosphorylation was analyzed by immunoblotting with the indicated antibodies.

\subsection{Coimmunoprecipitation}

Coimmunoprecipitation (co-IP) assays were performed in the whole cell lysates of HEK293 cells. For co-IP, $500 \mu \mathrm{L}$ of phosphate buffered saline (PBS) with protease and phosphatase inhibitors (1:100, Sigma-Aldrich, St. Louis, MO, USA) was used to dilute $500 \mu \mathrm{g}$ cell extracts in lysis buffer $(150 \mathrm{mM}$ $\mathrm{NaCl}, 50 \mathrm{mM}$ Tris $\mathrm{HCl}, \mathrm{pH} 7.6,1 \% \mathrm{NP}-40,0.1 \% \mathrm{SDS}$ ) overnight at $4{ }^{\circ} \mathrm{C}$. Samples precleared through incubation with Protein A/G agarose beads (Oncogene Science) were added to the lysate, and the mixture was incubated with shaking for $2 \mathrm{~h}$ at $4{ }^{\circ} \mathrm{C}$. The beads were spun down and washed three times with immune antibody precipitation assay buffer. Proteins binding to the beads were eluted by adding $20 \mu \mathrm{L}$ of $2 \times$ electrophoresis sample buffer and analyzed through immunoblotting with an anti-HA (Cat\#11666851001) or anti-GFP (Cat\#11814460001) antibody (Roche, Basel, Switzerland).

\subsection{Study Groups and CSF Samples}

Samples from a total of 20 participants were collected and categorized into four groups: Normal, $\mathrm{AD}$, neurological disorders (NAD), and mild cognitive impairment (MCI). CSF biomarkers and the impairment of different cognitive domains were evaluated as previously described [28]. Lumbar puncture (performed at the L3/L4 or L4/L5 interspace) was used to obtain CSF samples from participants at the Kaohsiung Veterans General Hospital (KVGH) after the participants had provided informed consent. This study was approved by the KVGH Institutional Review Board. Approximately $5 \mathrm{~mL}$ of CSF was withdrawn during the lumbar puncture. After collection, samples were spun at $3000 \mathrm{rpm}$ at $4{ }^{\circ} \mathrm{C}$ for $10 \mathrm{~min}$ to remove any cells or debris and were then transferred to a freezer and stored at $-80^{\circ} \mathrm{C}$ until use. Only CSF samples without visible blood were centrifuged, and the total Tau protein was further analyzed using Western blot assays in several CSF samples from each of the four groups to ensure that the total protein for each lane loading was $4 \mu \mathrm{g}$. 


\section{7. iPSC Lines Genotyping and Exome Sequencing}

Normal control iPSC lines, NTUH-iPSC-01-05 and NTUH-iPSC-02-02 (abbreviated as N1 and N2, respectively), were purchased from the Bioresource Collection and Research Center of Food Industry Research and Development Institute, Taiwan. The biopsy samples, one APP $\left({ }^{\mathrm{D} 678 \mathrm{H}}\right)$, one $A p o E 4\left(^{(\varepsilon / \varepsilon 4}\right)$, and one PSEN1 ( $\left.{ }^{\mathrm{P} 117 \mathrm{~L}}\right)$, were used to obtain iPSC lines from subjects at the Taipei Veterans General Hospital (TVGH) and upon informed patient consent. Genomic DNA was isolated from peripheral leukocytes using a DNA Extraction Kit (Stratagene, La Jolla, CA, USA). The APP, ApoE4, and PSEN1 genotype were determined by PCR amplification, gel purification, Hinfl digestion, and direct sequencing using an ABI PRISM 3730 Genetic Analyzer (Applied Biosystems, Forster City, CA, USA). Each PCR included $20 \mathrm{ng}$ of genomic DNA, $0.9 \mu \mathrm{M}$ of each primer, and Universal PCR Master Mix (Applied Biosystems, Forster City, CA, USA). Such as, direct sequencing of APP exon 16 PCR products derived from the patient and from healthy controls revealed a GAC-to-CAC nucleotide substitution in $\mathrm{Ab}$ region of the patient's $A P P$ gene (in 678th amino acid using $A P P^{770}$ numbering). The PCR conditions were as follows: $95^{\circ} \mathrm{C}$ for $5 \mathrm{~min}$, followed by 40 cycles of $95^{\circ} \mathrm{C}$ for $40 \mathrm{~s}, 58^{\circ} \mathrm{C}$ for $30 \mathrm{~s}$, and $72{ }^{\circ} \mathrm{C}$ for $40 \mathrm{~s}$, with a final extension at $72{ }^{\circ} \mathrm{C}$ for $10 \mathrm{~min}$.

\subsection{Generation and Culture of Human iPSC}

The biopsy samples of $\mathrm{AD}$ patients with $A P P^{\mathrm{D} 678 \mathrm{H}}, A p o E 4^{\varepsilon 4 / \varepsilon 4}$, or $P S E N 1^{\mathrm{P} 117 \mathrm{~L}}$ mutation were reprogrammed into iPSCs by Vesicular stomatitis virus G (VSV-G) coated Sendai viral transduction of four transcription factors, octamer-binding transcription factor 3/4 (OCT3/4), SRY (sex determining region Y)-box 2 (SOX2), Krüppel-like factor 4 (KLF4), and c-Myc (CytoTune-iPS reprogramming kit, Thermo Fisher Scientific, USA). The establishment of AD-iPSC lines followed the Policy Instructions on the Ethics of Human Embryo and Embryonic Stem Cell Research in Taiwan. In addition, approval from the Ethic Institutional Review Board and informed consent was also obtained from Taipei Veterans General Hospital and National Yang-Ming University. The successful iPSC clones exhibited typical characteristics of pluripotent stem cells and normal karyotypes, and the differentiation ability was confirmed in vivo by teratoma formation assay, and in vitro by the formation of three germ layers via embryoid bodies (Supplementary Figure S2) as also previously described $[29,30]$. Human iPSC lines were routinely maintained in Essential 8 Medium (E8, Invitrogen Life Technologies, Carlsbad, CA, USA) on cell culture dishes coated with $0.5 \mu \mathrm{g} / \mathrm{cm}^{2}$ recombinant human vitronectin (Invitrogen Life Technologies, Carlsbad, CA, USA). To passage iPSCs, the cells were washed twice with sterilized Dulbecco's PBS (DPBS; Invitrogen Life Technologies, Carlsbad, CA, USA) without calcium or magnesium and then incubated with DPBS/ethylenediaminetetraacetic acid (EDTA; $0.5 \mathrm{mM}$ UltraPure EDTA in DPBS) at $37^{\circ} \mathrm{C}$ for $3 \mathrm{~min}$. When the cells began to separate and round up, the DPBS/EDTA was removed, and the cells were washed swiftly from the vessel. An appropriate number of cells was transferred to a new culture dish and maintained in an incubator at $37^{\circ} \mathrm{C}$ under $5 \% \mathrm{CO}_{2}$. The cells were subcultured every $4-5$ days and then reseeded at a 1:5 to 1:10 ratio. The culture medium was refreshed daily.

\subsubsection{Generation of Isogenic iPSC Lines Using CRISPR/Cas9 Technology}

DNA oligonucleotides used for gRNA targeting were designed with the GeneArt CRISPR gRNA Design Tool (Thermo Fisher Scientific; Invitrogen Life Technologies, Carlsbad, CA, USA). To examine the cleavage efficiency of gRNA, a series of gRNAs flanking the target site was designed and synthesized. Each individual gRNA was combined with Cas9 nuclease (Invitrogen Life Technologies, Carlsbad, CA, USA) to form Cas9 protein/gRNA ribonucleoprotein complexes (Cas9 RNPs). The Cas9 RNPs were then used to transfect the iPSCs, a task for which the Neon Transfection System (Invitrogen Life Technologies, Carlsbad, CA, USA) was used. Genomic editing efficiency was then evaluated through T7 Endonuclease I (T7E1) assay $48 \mathrm{~h}$ after transfection. The gRNAs that had both the highest cleavage efficiencies and closest proximity to the target site were selected for the subsequent genome editing. 
For precise genome editing, the Cas9 RNPs and repair template (ssODN from IDT, Coralville, IA, USA) were coelectroporated into the iPSCs. The transfected iPSCs were then clonally expanded to derive isogenic cell lines. The single-nucleotide substitution was screened using a TaqMan SNP Genotyping Assay (Applied Biosystems, Forster City, CA, USA) and confirmed through Sanger sequencing.

\subsubsection{RNA Isolation and RT-PCR}

Total RNA was isolated using a Tissue Total RNA Mini Kit (Geneaid, Taipei, Taiwan) by following the manufacturer's instructions. In-column DNase I digestion was performed to remove genomic DNA contamination. Reverse transcription was then performed using Superscript IV (Invitrogen Life Technologies, Carlsbad, CA, USA) and Oligo $(\mathrm{dT})_{20}$ primers by following the manufacturer's guidelines. For PCR amplification, it was done with a denaturation step at $94{ }^{\circ} \mathrm{C}$ for $5 \mathrm{~min}$, followed by 35 cycles of denaturation at $94{ }^{\circ} \mathrm{C}$ for $30 \mathrm{~s}$, primer annealing at $60^{\circ} \mathrm{C}$ for $30 \mathrm{~s}$, and primer extension at $72{ }^{\circ} \mathrm{C}$ for $1 \mathrm{~min}$. Upon completion of the cycling steps, a final extension at $72{ }^{\circ} \mathrm{C}$ for $5 \mathrm{~min}$ was done and then the reaction was analyzed by DNA gel electrophoresis. The primers for PCR analysis are listed in supplementary Table S1.

\subsubsection{Karyotyping}

Chromosomal analysis was performed by G-banding analysis at the Cytogenetic Center of Ko's Obstetrics and Gynecology Clinic, Taipei, Taiwan, following the International System Cytogenetics Nomenclature recommendations.

\subsubsection{In Vivo Teratoma Formation}

The human induced pluripotent stem cell (hiPSC) colony was dissociated and resuspended in PBS. $2-5 \times 10^{6}$ cells per mouse were subcutaneously implanted into the dorsal flanks of SCID mice. Teratoma growth was monitored weekly and mice were sacrificed at 10 weeks post implantation. Teratomas were collected, fixed in formaldehyde, embedded in paraffin, sectioned and stained with hematoxylin and eosin (H\&E) for histological analysis.

\subsubsection{In Vitro Embryoid Body (EB) Formation}

hiPSC colonies were treated with collagenase IV (GIBCO BRL Life Technologies, Invitrogen Life Technologies, Carlsbad, CA, USA) and gently scraped off the culture dishes. After centrifugation, cells were resuspended in the EB medium (DMEM/F12 supplemented with 20\% KnockOut ${ }^{\text {TM }}$ Serum Replacement (KOSR, GIBCO BRL Life Technologies, Invitrogen Life Technologies, Carlsbad, CA, USA), 2 mM Glutamax, 1\% MEM non-essential amino acids (MEM-NEAA), and $55 \mu \mathrm{M}$ 2-mercaptoethanol) and transferred into low attachment dishes. EBs were cultured in a $37^{\circ} \mathrm{C}$ incubator with humidified atmosphere of $5 \% \mathrm{CO}_{2}$. The medium was changed every other day. After 14 days EBs were collected and assessed by RT-PCR for expression of stem cell and differentiation markers.

\subsubsection{Immunofluorescent Staining}

hiPSCs were fixed in 4\% paraformaldehyde in PBS for 20 min at room temperature, washed three times with PBS, and then incubated in $0.1 \%$ Triton X-100 in PBS for 5 min at room temperature. Next the cells were blocked in PBS containing 3\% bovine serum albumin (Sigma-Aldrich, St. Louis, Missouri, USA) and $1 \%$ goat serum (GIBCO BRL Life Technologies, Invitrogen Life Technologies, Carlsbad, USA) for $1 \mathrm{~h}$ at room temperature. The primary rabbit anti-Oct4 antibody (GeneTex, Irvine, CA, USA) was applied at the indicated concentration overnight at $4{ }^{\circ} \mathrm{C}$. Next the cells were washed in PBS three times and then the secondary antibody, goat anti-rabbit $\operatorname{IgG}(\mathrm{H}+\mathrm{L})$ - Alexa Fluor 555 (Thermo Fisher Scientific; GIBCO BRL Life Technologies, Invitrogen Life Technologies, Carlsbad, CA, USA), was applied for $1 \mathrm{~h}$ at room temperature. Fluorescent images were captured using a Zeiss microscope and an Andor Zyla cMOS camera and then processed using ImageJ software (NIH, Bethesda, MD, USA). 


\subsubsection{Lentivirus Production and Infection}

The lentiviral vector pTet-O-Ngn2-puro was a gift from Marius Wernig (Addgene plasmid \#52047). For lentivirus production, HEK 293T cells were seeded at $5 \times 10^{6}$ cells in a $10 \mathrm{~cm}$ dish and incubated overnight. Cells were cotransfected with $6 \mu \mathrm{g}$ of pTet-O-Ngn2puro or pFUW-rtTA with 5 $\mu \mathrm{g}$ of packaging plasmid pCMV- $\Delta 8.91$ and $1 \mu \mathrm{g}$ of envelope plasmid pVSV-G with Lipofectamine 3000 (Invitrogen Life Technologies, Carlsbad, CA, USA) following the manufacturer's instructions. The supernatant was collected at 24 and $72 \mathrm{~h}$ after transfection, filtered through a $0.45-\mu \mathrm{m}$ filter to remove cell debris, and then purified using the Lenti-X Maxi purification kit (TaKaRa Bio Inc., Otsu, Shiga, Japan). Virus concentrates were aliquoted at $100 \mu \mathrm{L}$ and stored at $-80^{\circ} \mathrm{C}$ until use. For iPSC transduction, approximately $2 \times 10^{4}$ iPSCs in one well of a 24 -well plate were infected with lentivirus containing rtTA. The next day, the medium was replaced with fresh E8 with lentivirus containing pTet-O-Ngn2-puro. The lentivirus-infected iPSCs were passaged and expanded for neuronal differentiation 3 days after transduction.

\subsubsection{Generation of Induced Neurons from iPSC}

The iPSCs were treated with $0.5 \mathrm{mM}$ EDTA and plated as dissociated cells in E8 medium containing $5 \mu \mathrm{M}$ Y-27632 (MedChemExpress, Monmouth Junction, NJ, USA) at a density of $10^{5}$ cells $/ \mathrm{mL}$ on vitronectin-coated dishes on day -1 . On day 0 , the culture medium was replaced with N2/DMEM/F12/NEAA containing human brain-derived neurotrophic factor (BDNF, $10 \mathrm{mg} / \mathrm{L}$, Peprotech, Inc., Rocky Hill, NJ, USA), human NT-3 (Neurotrophin-3, 10 mg/L, Peprotech, Inc., Rocky Hill, NJ, USA), mouse laminin ( $0.2 \mathrm{mg} / \mathrm{L}$, Invitrogen Life Technologies, Carlsbad, CA, USA), and doxycycline $(2 \mathrm{mg} / \mathrm{L})$. On day 1 , a $24 \mathrm{~h}$ puromycin selection $(1 \mathrm{mg} / \mathrm{L})$ period began. On day 2 , transfected cells were replated in neurobasal medium supplemented with B27/Glutamax (Invitrogen Life Technologies, Carlsbad, CA, USA) containing BDNF and NT-3. On day 5, Ara-C (2 $\mu \mathrm{M}$, Sigma-Aldrich, St. Louis, Missouri, USA) was added to the medium for $24 \mathrm{~h}$ to inhibit proliferation of undifferentiated cells. Subsequently, half the medium in each dish was changed every 3-4 days. Induced neurons were assayed on day 28 in most experiments.

\subsection{Western Blot Analysis}

Protein lysates were prepared as described previously [31]. Western blot analysis was performed with primary antibodies for GFP (sc-9996, 1:2000), Tau 46 (sc-32274, 1:500), and $\beta$-actin (sc-47778, 1:1000) were obtained from Santa Cruz Biotech (Santa Cruz, CA, USA).

Phospho-GSK-3 $\alpha / \beta$ (Ser21/9, 9331s, 1:1000), Phosphor-(Ser/Thr) PKA Substrate (9621s, 1:1000), and Phosphor-Tau (Ser396, PHF13, 9632s, 1:1000) were obtained from Cell Signaling. GSK-3 $\beta$ (Clone 7, 610202, 1:1000) and Drp1 (Clone 8/DLP1, 611112, 1:1000) were obtained from BD Transduction Laboratories. Tau 5 (QF215086, 1:1000), PhosphorTau (Thr205, 44-738G, 1:2000), Phosphor-Tau (Thr214, 44-742G, 1:2000), Phosphor-Tau (Thr231, 44-746G, 1:2000) and (Thr262, 44-750G, 1:2000) were obtained from Thermo Scientific. Phosphor-Tau (Ser409, AB9662, 1:2000) was obtained from Merck Millipore. Albumin (ab106582, 1:1000) was obtained from Abcam. HA monoclonal (H9658, 1:1000) was obtained from Sigma-Aldrich. PKA RII Subunits (06-411, 1:1000) was obtained from EMD Millipore.

\subsection{Statistical Analysis}

Statistical significance was evaluated through one-way analysis of variance followed by Tukey's post hoc test to correct for multiple comparisons. A two-tailed Student's $t$-test was used to compare data between two groups. Statistical significance was set as $p<0.05$. 


\section{Results}

\subsection{PKA, GSKIP, GSK3 $\beta$, and Tau May Form a Local Working Complex}

We recently identified residue L130 of GSKIP as a critical point for binding with GSK3 $\beta$, and the L130P GSKIP mutant resulted in loss of inhibition of neurite outgrowth in human neuroblastoma SH-SY5Y cells [5]. Further studies have demonstrated that mammalian GSKIP favors dimer instead of monomer because the V41/L45 sites are distal to the L130 residue in the GSKIP monomer formation, thus preventing mutual interactions between PKA RII and the GSK3 $\beta$ binding region, indicating that L130 point mutation is essential for the GSK3 $\beta$ binding function [7,9]. To determine whether GSKIP/GSK-3 $\beta /$ Tau could form an assembly, co-IP assay using GFP-Tau was used to pull down GSK3 $\beta$, GSKIP, and PKA RII, as shown in Figure 1. In addition, the complex binding ability of GSKIP was a total loss in the L130P mutant form (Figure 1, right panel, line 3 in lane 3). Moreover, our data showed that PKA RII could not be pulled down by either V41P/L45P or the L130P mutant (Figure 1, right panel, line 4 in lanes 2 and 3; compare with lane 1), both GSKIP V41P/L45P and GSKIP L130P mutants which resulted in PKA RII disassemble from the Tau/GSK3 $\beta$ complex (Figure 1, left panel, line 4 in lanes 2 and 3; compare with lane 1), indicating complex destruction by the mutants. This is consistent with our previous observations concerning Drp1 and $\beta$-catenin $[7,9]$. Altogether, these data suggest that GSKIP may function as an AKAP and recruit the PKA RII subunits with GSK3 $\beta$ and Tau into close proximity to form a complex (Figure 1).
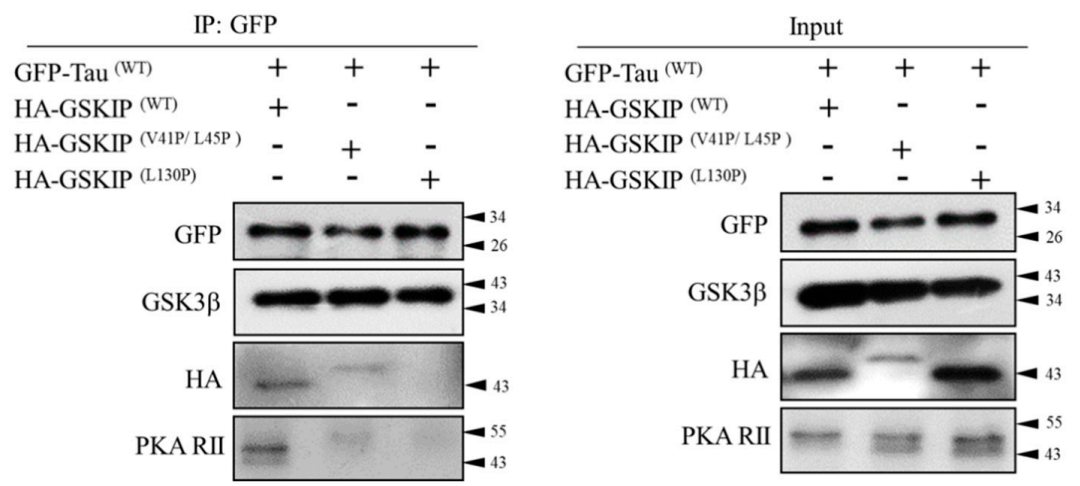

Figure 1. Tau interacts with glycogen synthase kinase $3 \beta$ (GSK3 $\beta$ ), GSK3 $\beta$ interaction protein (GSKIP), and protein kinase A (PKA) in HEK293 cells. pEGFP-C1-Tau, pET32a-HA-GSKIP (L130P), or pET32a-HA-GSKIP (V41/L45P) transfected cells were collected, and total lysates were subjected to IP using anti-GFP antibody. The resulting precipitates were then analyzed through immunoblotting with anti-GFP, GSK3 $\beta$, HA, and PKA antibodies.

\subsection{Knockdown Experiments Revealed that GSKIP and GSK3 $\beta$ Are Involved in cAMP/PKA/Tau Axis} Signaling in SH-SY5Y Cells

To protect neurons against oxidative stress, GSKIP L130 and Drp1 phosphorylation are critical points for the interaction between GSKIP/GSK3 $\beta$ and GSK3 $\beta /$ PKA complexes, respectively [7]. Because

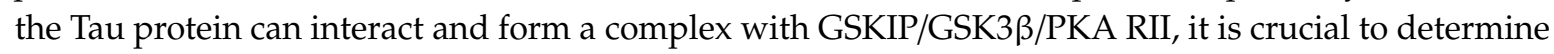
Tau's role in this complex. Therefore, we experimentally used forskolin (FSK) to activate PKA; the GSKIP V41P/L45P mutant suppressed Tau Ser409 phosphorylation, and GSKIP L130P enhanced Tau Ser409 phosphorylation (Figure 2A). The latter is not expected that may result from versatile conformation of phosphor-Tau. This result suggests that the physical interaction between PKA and GSKIP is related to Tau Ser409 phosphorylation. In addition, after PKA activation, overexpressed kinase-dead GSK3 $\beta$ K85R (retains capacity to bind GSKIP) but not K85M (loss of capacity to bind GSKIP) in SH-SY5Y cells had a higher level of phosphor-Tau at Ser409 (Figure 2B). This result suggests that the physical interaction between GSK3 $\beta$ and GSKIP is related to Tau Ser 409 phosphorylation, even under activated PKA. Moreover, in the presence of FSK, the silencing of GSK3 $\beta$ but not GSK3 $\alpha$ led to a 
decrease in Tau Ser409 phosphorylation (Figure 2C). We also examined the phosphorylation level of other sites of Tau in SH-SY5Y cells treated with FSK in different conditions. The results indicate that the phosphorylation levels of Ser409, Ser262, and Ser214 are increased by PKA but that of Tau Ser396 by GSK3 $\beta$ was slightly decreased (Supplementary Figure S1). The other two sites of phosphorylation of Tau by GSK3 $\beta$ Ser231 and Ser205 may not be involved in the GSKIP mediated pathway under FSK challenge (Supplementary Figure S1; compare with Figure 2A).

(A)

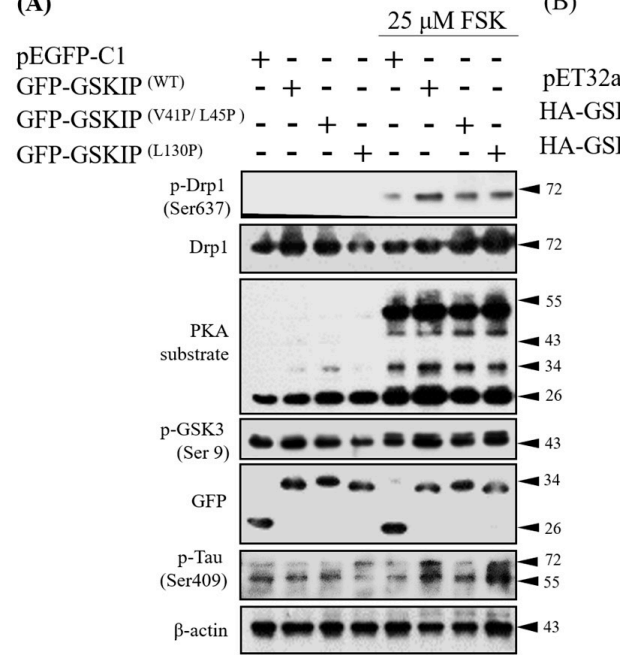

(B)

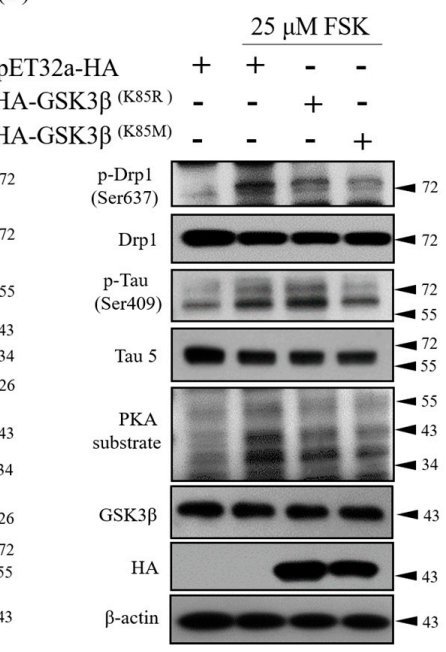

(C)

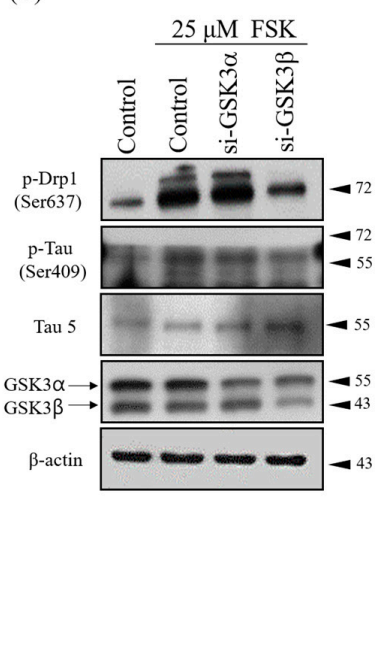

Figure 2. GSKIP through GSK3 $\beta$-mediated anchoring to modulate Tau phosphorylation by PKA kinase. (A) pEGFP-C1 or pEGFP-C1-GSKIP wt and mutants were transiently expressed in SH-SY5Y cells. The cells were untreated (left four lanes) or incubated with $25 \mu \mathrm{M}$ forskolin (FSK) for $1 \mathrm{~h}$ (right four lanes). (B) Kinase-inactive pET32a-HA-GSK3 $\beta$-K85R or -K85M mutants were transiently expressed in SH-SY5Y cells. pET32a-HA-GSK3 $\beta-K 85 R$ mutant retained the capacity to bind GSKIP, but such capacity was not evident in pET32a-HA-GSK3 $\beta$-K85M. Cells were incubated with $25 \mu \mathrm{M}$ FSK for $2 \mathrm{~h}$ and were then analyzed through Western blotting. (C) Knockdown of GSK3 $\beta$ but not GSK3 $\alpha$ expression altered phosphorylation of dynamin related protein 1 (Drp1) Ser637 and Tau Ser409.

These observations again suggest that GSK3 $\beta$ acts as a scaffold protein that recruits Tau to PKA, probably through Tau phosphorylation at Ser409. These data indicate that GSKIP and GSK3 $\beta$ coordinate to strengthen cAMP/PKA/Tau axis signaling. In addition, we observed that Tau phosphorylation at Ser409 is mediated not through GSK3 $\beta$ activity but through PKA signaling. Notably, this ensures that GSK $3 \beta$ acts solely as an anchor binding protein rather than relying on its kinase activity in this signaling axis.

\subsection{Site-Specific Effects of Prephosphorylation of Tau by PKA on the Subsequent Phosphorylation by GSK3 $\beta$ and CaMKII}

Phosphorylation of Tau at multiple sites is regulated by several kinases, most notably GSK3 $\beta$ (Tau ser205, Tau ser231, Tau ser396; in AD and control brains), PKA (Tau ser214, Tau ser262, Tau ser409; only in AD brains), and CaMKII (Tau Ser212, Tau Ser214, Tau Ser262, Tau Ser356, Tau Ser416; Table 1) [27,32-35]. To determine the role of Tau Ser409 phosphorylation on the cAMP/PKA/Tau axis and to examine whether the phosphorylation sites are modulated by other kinase phosphorylation priming, we used in vitro kinase assay with phosphorylation-specific Tau antibodies to detect Tau phosphorylation at various sites after incubation of total Tau with PKA, GSK3 $\beta$, or CaMKII by different order (Figure 3A). The data showed that phosphorylation of Tau at Ser205, Ser231, and Ser396 was associated with GSK3 $\beta$, whereas phosphorylation at sites Ser214, Ser262, and Ser409 was associated with PKA. Regardless of pre-incubation with PKA, the GSK3 $\beta$ phosphorylation sites on Tau were always the same. However, the PKA phosphorylation sites on Tau exhibited an interesting result in 
that Tau Ser409 significantly decreased fourfold after incubating with GSK3 $\beta$ (Figure 3A, lanes 4 and 5; compare with lane 3). This result indicated the masking effect of GSK3 $\beta$, which induced protein conformation alteration that blocked PKA binding with Tau. This effect on Tau phosphorylation was also evident with CaMKII and PKA cotreatment, but it seems to have been unrelated to all PKA Tau sites, including Ser214, Ser262, and even Ser409 (Figure 3B). These results indicate a specific Tau phosphorylation pattern in which each kinase is alone or in any combination of two different kinases, but especially GSK3 $\beta$ plus PKA (Figure 3A). Therefore, we next assessed the hyperphosphorylation of Tau conformation to determine whether this novel finding has added benefit for AD assessments. We undertook experiments to determine the Tau phosphorylation level in the CSF of different types of AD patients to determine whether it could serve as a diagnostic biomarker.

Table 1. List of Tau-specific phosphorylation sites for PKA, GSK3 $\beta$, and CaMKII.

\begin{tabular}{ccc}
\hline \multirow{2}{*}{ Kinase } & $\begin{array}{c}\text { Specific Phosphorylated Site for } \\
\text { Tau }\end{array}$ & Ref. \\
& Ser214 & Liu et al., 2006 [35], Liu et al., 2008 \\
PKA & [32], Zhu et al., 2010 [33], Oliveira \\
& et al., 2017 [34] \\
\hline & Ser409 & \\
GSK3 $\beta$ & Ser205 & \\
& Ser231 & Liu et al., 2006 [35], Wang et al., \\
& Ser396 & 2007 [36], Liu et al., 2008 [32], \\
& Ser404 & Oliveira et al., 2017 [34] \\
\hline \multirow{3}{*}{ CaMK II } & Ser212 & \\
& Ser214 & \\
& Ser262 & Liu et al., 2006 [35], Wang et al., \\
& Ser356 & Oliveira et al., 2017 [34] \\
& Ser416 & \\
\hline
\end{tabular}

PKA, protein kinase A; GSK3 $\beta$, glycogen synthase kinase $3 \beta$; CaMKII, Ca2+/calmodulin-dependent protein kinase II.

\subsection{Total and Phosphorylated Tau of CSF in AD, NAD, and MCI Patients}

It is well-known that hyperphosphorylation of Tau promotes the accumulation of Tau protein and its binding ability to microtubules $[17,35]$. Therefore, the Tau phosphorylation level of CSF in AD, NA, and MCI patients may serve as a diagnostic indicator. We first compared CSF Tau and phosphorylation Tau among AD, NAD, and MCI patients. The total Tau concentration, PKA phosphorylation sites on Tau (Ser214, Ser262, and Ser409), and GSK3 $\beta$ phosphorylation sites on Tau (Ser205, Ser231, and Ser396) were evaluated from CSF, as shown in Figure 4. We observed a higher level of phosphor-Tau (Ser214, Ser262, and Ser409) by PKA in the AD group when compared with the normal group, but significant differences were not found among the NAD, MCI, and normal groups. The results also showed that Tau phosphorylation by GSK3 $\beta$ at the Ser205, Ser231, and Ser396 sites occurred in the normal, AD $\left(A P P^{\mathrm{D} 678 \mathrm{H}}\right), \mathrm{NAD}$, and $\mathrm{MCI}$ groups, a finding consistent with those previously reported regarding Tau hyperphosphorylation sites [28,37] that indicated the phosphor-Tau sites in AD and normal brains [38]. 
(A)

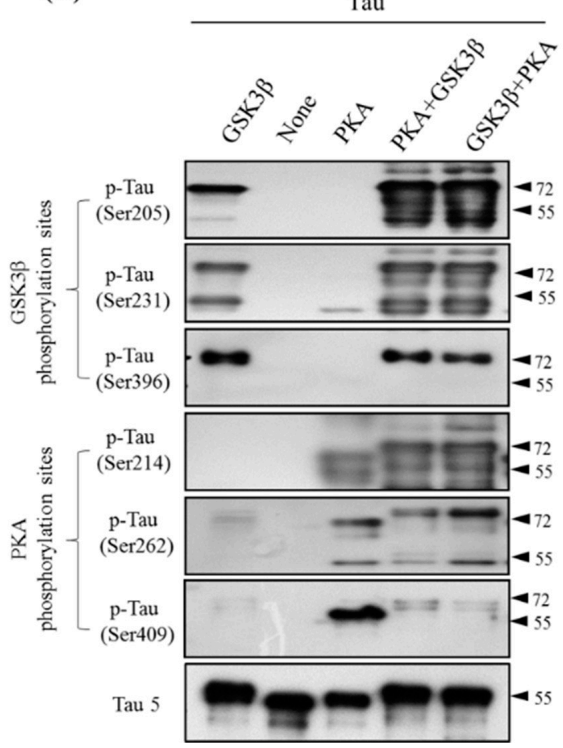

(B)

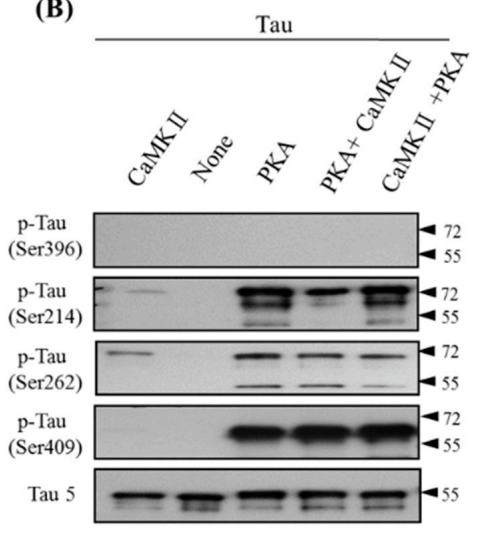

Figure 3. Site-specific phosphorylation of Tau by PKA or GSK3 $\beta$ and Ca2+/calmodulin-dependent protein kinase II (CaMKII). (A) Site-specific effects of prephosphorylation of Tau by PKA on the subsequent phosphorylation by GSK-3 $\beta$. Recombinant Tau was phosphorylated by GSK3 $\beta$ and PKA for $3 \mathrm{~h}$ (lines 1, 3, respectively); line 2 shows the control-treated Tau. Tau was first phosphorylated by PKA for $1 \mathrm{~h}$ and then incubated with GSK3 $\beta$ kinase for $120 \mathrm{~min}$ (line 4); then, it was phosphorylated by GSK3 $\beta$ for $1 \mathrm{~h}$, followed by incubation with PKA kinase for $120 \mathrm{~min}$ (line 5). (B) Site-specific effects of prephosphorylation of Tau by PKA on the subsequent phosphorylation by CaMKII.
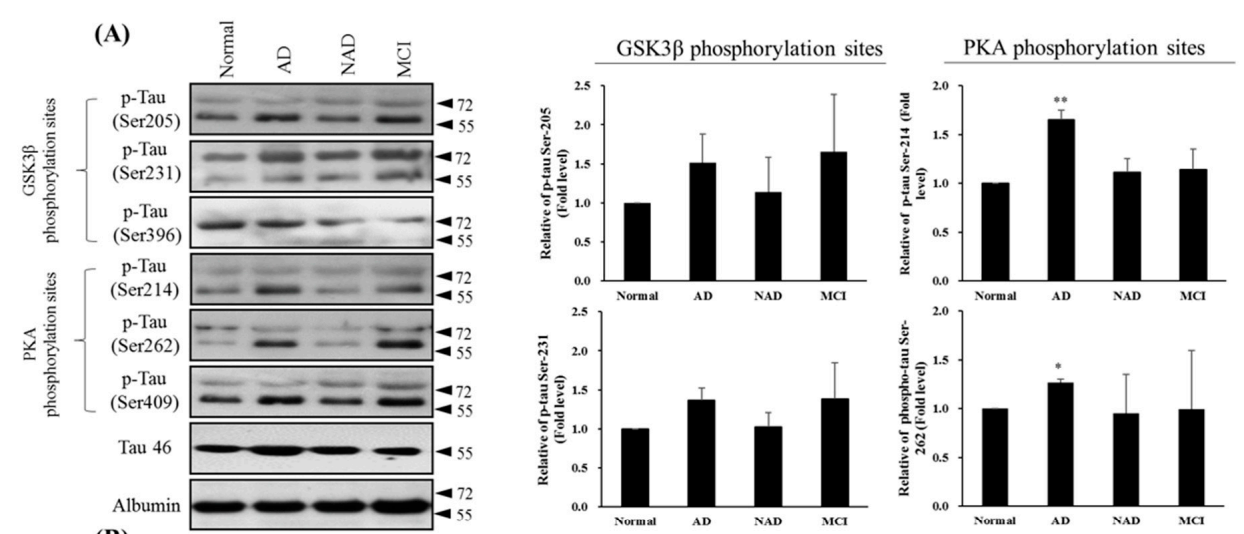

(B)
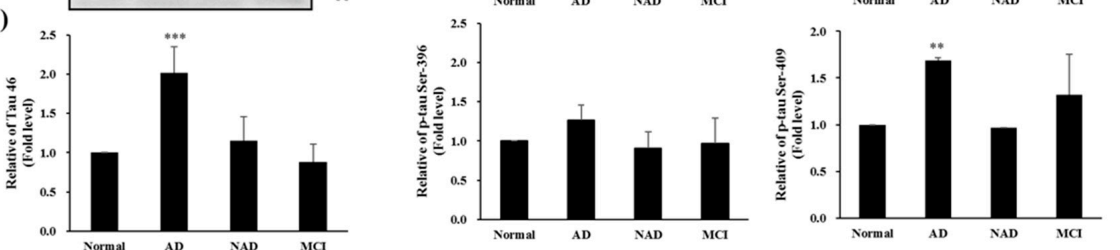

Figure 4. Western blot of Tau46 (total Tau) and phosphorylated Tau by GSK3 $\beta$ and PKA kinases from cerebrospinal fluid (CSF) sampling of four groups: normal, Alzheimer's disease (AD), neurological disorders (NAD), and mild cognitive impairment (MCI). (A) Western blotting with Tau 46, Tau Ser205, Tau Ser231, and Tau Ser396 by GSK3 $\beta$ or Tau Ser214, Tau Ser262, and Tau Ser409 by PKA antibodies. Albumin was used as an internal control. (B) Statistical analysis. Bar graphs represent the mean \pm SD of triplicates. ${ }^{*} p<0.05,{ }^{* *} p<0.01,{ }^{* * *} p<0.001$ compared with the control group. 


\subsection{Phosphorylation of Tau in AD-iPSC-Derived Neurons with CRISPR/Cas9}

Several $\mathrm{AD}$ cases were reported to carry the $A P P^{\mathrm{D} 678 \mathrm{H}}$ mutation, which is also called the Taiwanese mutation $[24,25,38-41]$. The use of CRISPR/Cas technology for genome editing has many potential applications [26]. To mimic the clinical situation of AD, previously generated iPSCs from an $\mathrm{AD}$ patient carrying heterozygous $A P P^{\mathrm{WT} / \mathrm{D} 678 \mathrm{H}}$ were further edited using Cas9-gRNA cleavage to create isogenic homozygous control $A P P^{\mathrm{WT} / \mathrm{WT}}$ and $A P P^{\mathrm{D} 678 \mathrm{H} / \mathrm{D} 678 \mathrm{H}}$ (Table 2, Figure 5A,B; [37]). The isogenic iPSC clones exhibited typical characteristics of pluripotent stem cells: Similar morphology to embryonic stem cells (ESCs) and expression of pluripotent marker OCT3/4 (Supplementary Figure S2A-D). To extend the clinical significance of Tau phosphorylation status in AD, the isogenic iPSC lines were thus differentiated into gluatamatergic neurons, which are severely lost in AD brains, using the Neurogenin 2 (Ngn2) induction method (Supplementary Figure S2E). The iPSC-derived neurons displayed somatodendritic and axonal markers, microtubule-associated protein 2 (MAP2) and neurofilament (Smi-312), respectively, as well as exhibited neuronal activity (Supplementary Figure S2F). Furthermore, we found no obvious difference in the ability to generate induced neurons between isogenic lines, suggesting the $A P P^{\mathrm{D} 678 \mathrm{H}}$ mutation has no significant effect on neuronal differentiation. To determine whether AD-iPSC-derived neurons recapitulated Tau and phosphorylated AD Tau, we examined the Tau and phosphorylated Tau levels in the AD-iPSC-derived neurons; we found higher levels of PKA phosphorylation on Tau sites Ser214, Ser262, and Ser409 (Figure 5C,D). We also examined the levels of GSK3 $\beta$ phosphorylation on Tau sites Ser205, Ser231, Ser396 and found reduced phosphorylation (Tau Ser231) in the heterozygous $A P P^{\mathrm{WT} / \mathrm{D} 678 \mathrm{H}}$ mutation, isogenic control APPWT/WT, and $A P P^{\mathrm{D} 678 \mathrm{H} / \mathrm{D} 678 \mathrm{H}}$ compared with ctrl-iPSCs. This finding indicated that the phosphorylation of Tau Ser214, Ser262, and Ser409 by PKA was increased, whereas the phosphorylation of Tau Ser231 and Ser396 by GSK3 $\beta$ was decreased, resulting in no overall change in total Tau (Figure 5C,D). Further, we examined an intense level of all sites of phosphorylation by PKA (Tau Ser214, Ser262, and Ser409) in heterozygous $A P P^{\mathrm{WT} / \mathrm{D} 678 \mathrm{H}}$; the examination revealed elevated expression of GSKIP, suggesting that it is a key player (Figure 5E,F). These results were consistent with a previous study that demonstrated three sites of Tau phosphorylation by PKA, but not by GSK3 $\beta$, in the AD brain [34]. Furthermore, we did not observe these differences in Tau phosphorylation situations in the groups of ApoE4 and PSEN1 patients (Supplementary Figure S3) [26,42,43].

Table 2. Human iPSC (hiPSC) lines.

\begin{tabular}{|c|c|c|c|c|c|c|}
\hline hiPSC Lines & Gender & $\begin{array}{l}\text { Age at } \\
\text { Biopsy }\end{array}$ & Genotype * & $\begin{array}{l}\text { APOE } \\
\text { Status }\end{array}$ & $\begin{array}{c}\text { Clinical } \\
\text { Diagnosis at } \\
\text { Time of Biopsy }\end{array}$ & Note \\
\hline Ctrl & Female & 45 & WT & $\varepsilon 4 / \varepsilon 4$ & $\mathrm{~N} / \mathrm{A}$ & Unedited \\
\hline $\mathrm{APP} W \mathrm{WT} / \mathrm{WT}$ & Female & N/A & $\mathrm{APP} W \mathrm{WT} / \mathrm{WT}$ & $\varepsilon 3 / \varepsilon 4$ & $\begin{array}{c}\mathrm{N} / \mathrm{A} \\
\text { progressive }\end{array}$ & CRISPR-edited \\
\hline $\mathrm{APPWT/D678H}$ & Female & 63 & $\mathrm{APP} W \mathrm{~W} / \mathrm{D} 678 \mathrm{H}$ & $\varepsilon 3 / \varepsilon 4$ & $\begin{array}{l}\text { memory and } \\
\text { behavior } \\
\text { problems }\end{array}$ & Unedited \\
\hline APPD678H/D678H & Female & N/A & $\mathrm{APP}$ D678H/D678H & $\varepsilon 3 / \varepsilon 4$ & N/A & CRISPR-edited \\
\hline
\end{tabular}

${ }^{*}$ Exome sequencing of $A P P$, PS1 and PS2 genes. 
(A)

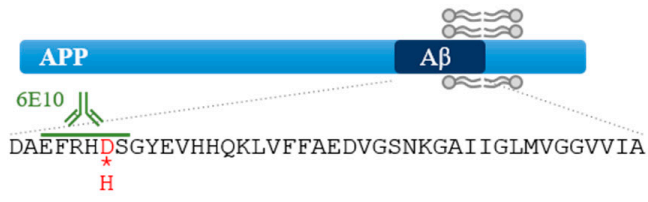

(B)

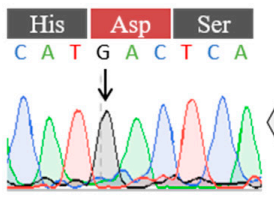

$\mathrm{APPWT} / \mathrm{WT}$
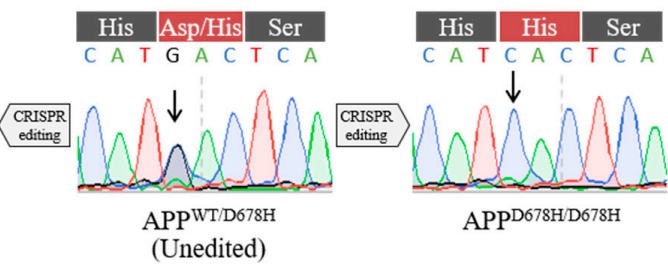

APPD678H/D678H

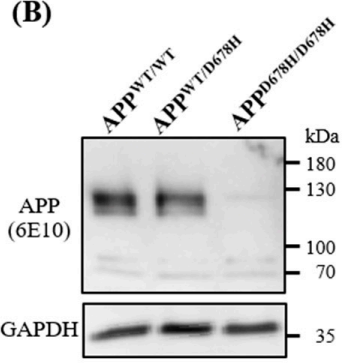

(C)

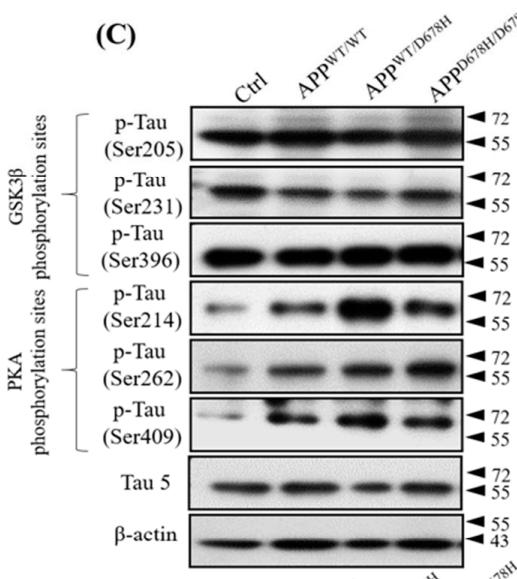

(E)

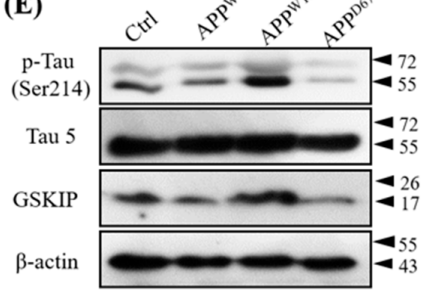

(D)<smiles>[AlH2]</smiles>

LillIIII

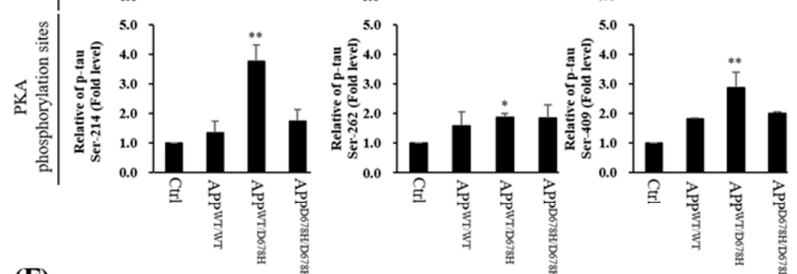

(F)

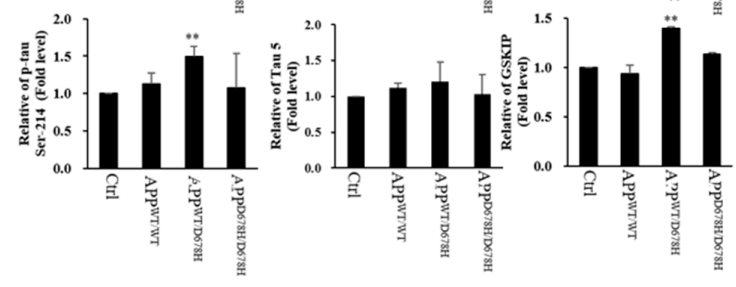

Figure 5. Tau phosphorylation in a patient-derived Alzheimer's disease induced pluripotent stem cell (AD-iPSC) line with amyloid precursor protein $\left(A P P^{\mathrm{WT} / \mathrm{D} 678 \mathrm{H}}\right)$ mutation cultured at 29 days. Isogenic control $\left({ }^{\mathrm{WT} / \mathrm{WT}}\right)$ and isogenic mutant $\left({ }^{\mathrm{D} 678 \mathrm{H} / \mathrm{D} 678 \mathrm{H}}\right)$ were generated by CRISPR/Cas9 gene editing and examined in parallel. (A) The diagram presents $A P P$ protein and the ${ }^{\mathrm{D} 678 \mathrm{H}}$ mutation within amyloid- $\beta$ $(\mathrm{A} \beta$ ) region in AD-iPSC (upper panel). Direct sequencing of APP exon 16 PCR products derived from the patient and from healthy controls revealed a GAC-to-CAC nucleotide substitution in A $\beta$ region of the patient's $A P P$ gene (in 678th amino acid using $A P P^{770}$ numbering or in 7 th amino acid using $\mathrm{A} \beta$ numbering) (lower panel). (B) Western blotting with 6E10 antibody, which recognizes residues 3-8 of $\mathrm{A} \beta$, was used to detect the expression of APP protein in D29 iPSC-derived neurons. GAPDH was used to confirm similar protein loading across samples. (C) Western blotting with antibodies of Tau 5, Tau Ser409, Tau Ser231, Tau Ser396 by GSK3 $\beta$ or Tau Ser214, Tau Ser262 and Tau Ser409 by PKA. Tau 5 (Total Tau) was used as an internal control compared with the control group. $\beta$-actin was used as an internal control. (D) Statistic analysis for (C). (E) Western blotting with GSKIP antibody. (F) Statistic analysis for (E). Bar graphs represent the mean of triplicates \pm SD. ${ }^{*} p<0.05,{ }^{* *} p<0.01,{ }^{* * *} p<0.001$.

\section{Discussion}

In this study, we identified a specific PKA phosphorylation site on Tau protein that was accompanied by GSK3 $\beta$ and GSKIP to form a working complex from the neuroblastoma cell line in clinical AD patients. We previously identified residue L130 of GSKIP as being critical for binding with GSK3 $\beta$, and cells with the L130P GSKIP mutant lose the inhibition of neurite outgrowth in human 
SH-SY5Y neuroblastoma cells [5]. We also demonstrated that mammalian GSKIP favors dimer instead of monomer formation because the V41/L45 sites are distal to the L130 residue in the GSKIP monomer; this prevents possible mutual interactions between PKA RII and the GSK3 $\beta$ binding region. We also determined that the L130P mutation is crucial for GSK3 $\beta$ binding $[7,9]$. Our data in Figure 1 reveal that the pET32a-HA-GSKIP (V41/L45P) mutant failed to interact with the PKA RII binding site (loss of function; negative regulation) and increased binding to GSK3 $\beta$ (gain of function; positive regulation), which is consistent with earlier reports [7,9]. These data suggest that GSKIP may function as an AKAP to recruit the GSK3 $\beta$, Tau, and PKA RII subunits into close proximity and that GSKIP forms a working model with PKA RII/GSK3 $\beta /$ Tau (Figure 6).

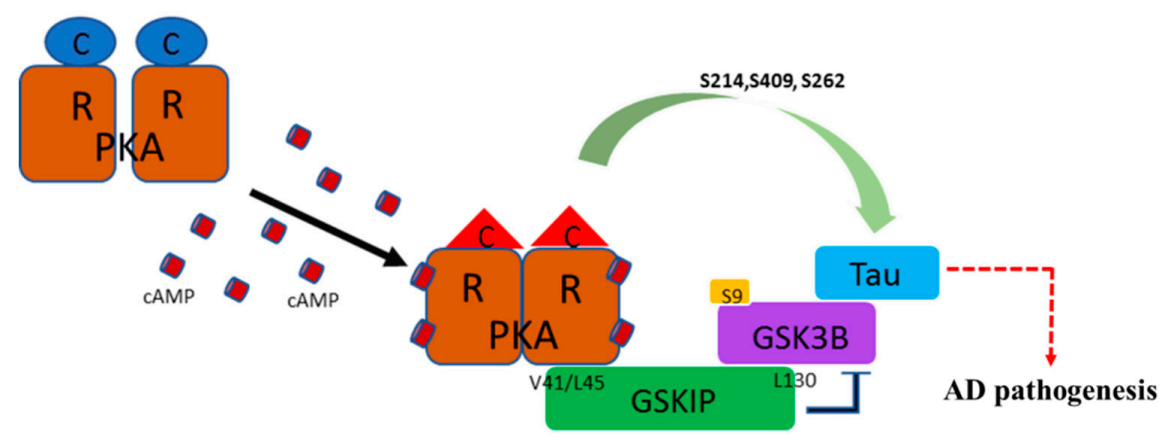

Figure 6. Schematic of GSKIP, GSK3 $\beta$, PKA RII, and Tau complex. While activating cAMP signaling, GSKIP wt conjugated with activated PKA to facilitate GSK3 $\beta$ Ser9 phosphorylation. GSKIP negatively regulates GSK3 $\beta$ activity (previously characterized in $[1,6,7,9]$ ); resulting in double inhibition of GSK3 $\beta$ activity and mediation of Tau phosphorylation by active catalytic form of PKA (red triangle). GSKIP anchors Tau through L130 by tethering GSK3 $\beta$ for PKA-mediated phosphorylation of Ser214, Ser262, and Ser409. This is thought to cause neuron tangles through Tau hyperphosphorylation. $\mathrm{R}$, regulatory subunit of PKA; C, catalytic subunit of PKA.

Previous studies have revealed that PKA RII directly phosphorylated Drp1 Ser637 via GSK3 $\beta$ as scaffold, and that Drp1 Ser637 phosphorylation was significantly reduced after removing the GSK3 $\beta$. In addition, the coordination of GSKIP and GSK3 $\beta$ has been shown to enhance the cAMP/PKA/Drp1 axis through the study of GSK3 $\beta$ K85R (retained GSKIP binding ability) and GSK3 $\beta$ K85M (loss GSKIP binding ability) $[1,6,7,9]$. In this study, both Drp1 Ser637 and Tau Ser409 phosphorylation were enhanced in the GSK3 $\beta$ K85R group and were reduced in the GSK3 $\beta$ K85M group. The phosphorylation signals of Drp1 Ser637 and Tau Ser409 were also reduced after knocking down GSK3 $\alpha$ and GSK3 $\beta$, as depicted in in Figure 2C. According to the results in Figure 2A,B, we can conclude three things. First, the interaction between GSKIP and GSK3 $\beta$ affects the efficiency of the complex, as evidenced by the GSKIP interaction with PKA (V41/L45) and GSK3 $\beta$ (L130). Second, when the cAMP signaling pathway was activated, PKA RII phosphorylated Tau Ser409 with the PKA/GSKIP/GSK3 $\beta$ complex, but GSK3 $\beta$ did not. Third, GSK3 $\beta$ only serves as a scaffold for anchoring PKA and Tau and is not a kinase in the complex.

There are at least 85 putative sites of phosphorylation in Tau, including 80 serine and threonine residues, and nearly half of them are phosphorylated to a certain extent in the AD brain. Tau phosphorylation is regulated by many kinases, including GSK3 $\beta$, cyclindependent kinase 5, mitogen-activated protein kinases, dual-specificity tyrosine-regulated kinase 1A, PKA, PKB/Akt, PKC, PKN, and CaMKII [27,32-35,44]. Mixed evidence points to a possible role of phosphor-Tau in AD, especially in the GSK3 $\beta$ character (Tau undergoes prior phosphorylation at a site four amino acids upstream of the phosphorylation site for S/TXXXS/T motif priming or the S/TP motif) [45-47]. The precise role of some of these kinases on Tau is still under investigation, with particular interest focused on GSK3 $\beta$, PKA, and CaMKII. Each of these three kinases or their combinations can phosphorylate Tau at multiple sites (for a summary of the phosphorylation sites see Table 1) [27,30-33]. When 
Tau is not interacting with other proteins, it may curl on its own, and this random curled state is thought to be important for preventing interactions with other Tau proteins by masking the possible interacting phosphorylated sites [48,49]. As evident in Figure 3, Tau Ser409, Ser214, and Ser262 were all phosphorylated under a PKA-only condition, whereas Tau Ser409 phosphorylation was dramatically reduced under either both PKA plus GSK3 $\beta$ and GSK3 $\beta$ plus PKA. Hyperphosphorylated Tau is a major constituent of NFTs.

Considerable evidence has suggested that Tau hyperphosphorylation occurs in the early stage of $\mathrm{AD}$ and other diseases caused by abnormal Tau expression [50-53]. The combinations of PKA plus GSK3 $\beta$ that resulted in phosphorylation of Tau site Ser 409 by PKA were underestimated (fourfold lower than expected). To determine whether this unique site of Tau Ser409 was identical in clinical application to in different types of $\mathrm{AD}$, we compared Tau phosphorylation in the CSF of normal, $\mathrm{AD}, \mathrm{MCI}$, and NAD patients. We determined that the CSF levels of total Tau are elevated in AD compared with the normal control, MCI, and NAD neurological control cases. Similar levels of total Tau were observed among the normal control, MCI, and NAD groups, suggesting that the rate of neurodegeneration in the NAD group was similar to that observed in the non-neurologically aged controls and normal patients (Figure 4A,B). The CSF levels of phosphor-Tau at PKA phosphorylation sites (Ser214, Ser262, and Ser409), especially relative to the total Tau levels, are elevated only in AD (Figure 4A,B). This phosphor-Tau at Ser409 caused by PKA in AD was not compatible with what we observed in in vitro kinase assay (Figure 3A, lanes 4 and 5; compare with Figure 4, lane Ser409 (in AD)). We believe this discrepancy may not be controlled simply by GSK3 $\beta$ or PKA but may be due to some regulatory mechanism at many phosphor-Tau sites, such as protein conformational changes which is versatile and possesses many tasks independently during AD pathogenesis (Figure 6). Tauopathic changes were noted only in the striata of Parkinson disease (PD) and PD with dementia, with increased hyperphosphorylation seen at Ser262 and Ser396 [54].

Tau Ser214 phosphorylation was identified in the early stage of $\mathrm{AD}$ and observe to persist through the formation of whole NFTs. Tau phosphorylation at Ser214 also has synergistic actions when combined with other kinases, and this accelerates Tau hyperphosphorylation at multiple sites [55]. Therefore, the specific phosphorylation sites of Tau may yield information concerning AD pathogenesis. These findings are consistent with a previous report in which elevated CSF levels of total Tau were observed in the early stages of AD [56]. Despite the GSKIP regulation of PKA-mediated Tau Ser214, Ser262, and Ser409 phosphorylation, the GSKIP protein concentration in CSF was undetectable in our AD patients, as determined through Western blot (Supplementary Figure S2). Confirming the interplay between Tau phosphorylation and the PKA/GSKIP/GSK3 $\beta$ complex may require evaluating CSF from APP patients. Our findings thus suggest that the increased level of PKA phosphorylation sites (Ser214, Ser262, and Ser409) in CSF is specific to AD and could be used as a diagnostic aid for AD. Furthermore, none of the patients in the control groups had any lesions of abnormally hyperphosphorylated Tau in their brains, and thus they exhibited low CSF levels of abnormally hyperphosphorylated Tau.

The shift of APP processing into the amyloidogenic pathway is one of the key factors in AD pathogenesis [57]. We transformed two AD-patient-delivered mononuclear cells to iPSCs, and they differentiated into neurons following the use of CRISPR/Cas9 to create APPWT and double $\mathrm{D} 678 \mathrm{H}$ mutants. The $A P P^{\mathrm{D} 678 \mathrm{H}}$ mutant facilitated $A P P$ sorting into the endosomal-lysosomal pathway and thus increased $A \beta$ production [39]. In this study, the signals of Tau Ser214, Ser262, and Ser409 phosphorylation (PKA target sites; see Table 1) exhibited a significant increase in the neurons derived from the $A P P^{\mathrm{WT} / \mathrm{D} 678 \mathrm{H}_{-} \mathrm{iPSC}}$ group, but the signal in Tau Ser231 (GSK3 $\beta$ target sites) was dramatically decreased. We found that the signals of Tau Ser214, Ser262, and Ser409 phosphorylation (PKA target sites) were reduced after editing back to WT/WT (Figure 5B,C). In addition to serving as the GSK3 $\beta$ blockade substrate, GSKIP also inhibited GSK3 $\beta$ onto phosphor-Tau through negative regulation. By contrast, a recent report showed that the neurons derived from $A P P^{\mathrm{D} 678 \mathrm{H}_{-}}$iPSC exhibited aberrant accumulation of intracellular material and secreted A $\beta 42$ and A $\beta 40$ in GSK3 $\beta$ hyperphosphorylation of Thr181 and Ser396 [25]. We believe the lack of change in the GSKIP protein 
level in the $A P P^{\mathrm{D} 678 \mathrm{H} / \mathrm{D} 678 \mathrm{H}}$-iPSC homologous mutant could be due to two possible mechanisms: The homo-type of $A P P^{\mathrm{D} 678 \mathrm{H} / \mathrm{D} 678 \mathrm{H}}$ may cause serious damage to iPSCs, or CRISPR/Cas9 technology may cause an off-target effect.

Since the continuous failure of $A \beta$-targeted therapeutics, the Phosphor-Tau has received much attention and highlights the urgency to consider alternative therapeutic strategies for AD [18]. In conclusion, we suggest that the PKA/GSKIP/GSK3 $\beta /$ Tau complex also plays a key role on the development of AD. In addition, total Tau and PKA phosphor Tau sites (Ser214, Ser262, and Ser409) in CSF and iPSCs are good feasibility of standard criteria for the detection of AD. Altogether, this study provides compelling evidence of the function of both GSKIP and GSK3 $\beta$ as anchoring proteins that enhance cAMP/PKA/Tau axis signaling during AD pathogenesis (Figure 6). Our findings suggest that phospho-Tau resulting from PKA and GSKIP could serve as a potential biomarker and could represent a new strategy for the detection and determination of the mechanism of pathogenesis in AD. Thus, integrating cAMP/PKA/Tau and GSKIP and $\mathrm{A} \beta 42$ and $\mathrm{A} \beta 40$ biomarkers for the detection of different types of $\mathrm{AD}$ and tauopathies and for the prediction of treatment outcomes could improve the clinical practice of precision medicine.

Supplementary Materials: The following are available online at http:/www.mdpi.com/2077-0383/8/10/1751/s1, Figure S1: GSKIP through PKA and GSK3 $\beta$ mediated Tau phosphorylation as an AKAP, Figure S2: Characterization of the iPSC lines and derived neurons, Figure S3: Increased Tau phosphorylation in iPSC-derived neurons from AD patients Table S1: Primers for RT-qPCR.

Author Contributions: The study was conceived and designed by C.-Y.H. and Y.-R.H. iPSCs were prepared by Y.-H.W. and M.-J.F. Western blotting, Co-IP, kinase assay, RNAi and data analysis were performed by H.-J.K., Y.-H.W., C.-H.C., Y.-L.L., A.-S.L., C.W., J.-K.L., J.-T.C., and S.-J.C. All other experiments were performed by Y.-T.L., P.-J.L., H.-J.K., Y.-H.W. and Y.-L.L., C.-Y.H., S.-J.C., Y.-H.W. and Y.-R.H. wrote the manuscript. All authors read and approved the final manuscript.

Funding: The study was supported by grants from the Ministry of Science and Technology (MOST) to YRH (Grant no: 107-2320-B-037-027: 108-2320-B-037-002) and C-YFH (MOST 103-2325-B-010006 and 107-2320-B-010-040-MY3); other funding sources were Kaohsiung Medical University, Kaohsiung Medical University Hospital, and the National Sun Yat-Sen University and Kaohsiung Medical University cooperative program (NSYSUKMU-107P006 and NSYSUKMU-108-P005), which provided grants to YRH.

Acknowledgments: We thank Wallace Academic Editing for English editing.

Conflicts of Interest: The authors declare they have no competing interests.

Ethics Approval and Consent to Participate: This study was approved by the Ethics Committees of TVGH and KVGH and followed the principles of the Helsinki Declaration II. Written informed consent was obtained from the legal guardians of the patients.

Patient Consent for Publication: The legal guardians of the patients involved in this study provided written informed consent prior to inclusion in the study.

\section{References}

1. Hundsrucker, C.; Skroblin, P.; Christian, F.; Zenn, H.M.; Popara, V.; Joshi, M.; Eichhorst, J.; Wiesner, B.; Herberg, F.W.; Reif, B.; et al. Glycogen synthase kinase 3beta interaction protein functions as an A-kinase anchoring protein. J. Biol. Chem. 2010, 285, 5507-5521. [CrossRef] [PubMed]

2. Skroblin, P.; Grossmann, S.; Schafer, G.; Rosenthal, W.; Klussmann, E. Mechanisms of protein kinase A anchoring. Int. Rev. Cell Mol. Biol. 2010, 283, 235-330. [PubMed]

3. Tang, X.N.; Lo, C.W.; Chuang, Y.C.; Chen, C.T.; Sun, Y.C.; Hong, Y.R.; Yang, C.N. Prediction of the binding mode between GSK3 $\beta$ and a peptide derived from GSKIP using molecular dynamics simulation. Biopolymers 2011, 95, 461-471. [CrossRef] [PubMed]

4. Howng, S.L.; Hwang, C.C.; Hsu, C.Y.; Hsu, M.Y.; Teng, C.Y.; Chou, C.H.; Lee, M.F.; Wu, C.H.; Chiou, S.J.; Lieu, A.S.; et al. Involvement of the residues of GSKIP, AxinGID, and FRATtide in their binding with GSK3beta to unravel a novel C-terminal scaffold-binding region. Mol. Cell. Biochem. 2010, 339, 23-33. [CrossRef] [PubMed] 
5. Lin, C.C.; Chou, C.H.; Howng, S.L.; Hsu, C.Y.; Hwang, C.C.; Wang, C.; Hsu, C.M.; Hong, Y.R. GSKIP, an inhibitor of GSK $\beta$, mediates the N-cadherin/betacatenin pool in the differentiation of SH-SY5Y cells. J. Cell. Biochem. 2009, 108, 1325-1336. [CrossRef]

6. Chou, H.Y.; Howng, S.L.; Cheng, T.S.; Hsiao, Y.L.; Lieu, A.S.; Loh, J.K.; Hwang, S.L.; Lin, C.C.; Hsu, C.M.; Wang, C.; et al. GSKIP is homologous to the Axin GSK3beta interaction domain and functions as a negative regulator of GSK3 $\beta$. Biochemistry 2006, 45, 11379-11389. [CrossRef]

7. Loh, J.K.; Lin, C.C.; Yang, M.C.; Chou, C.H.; Chen, W.S.; Hong, M.C.; Cho, C.L.; Hsu, C.M.; Cheng, J.T.; Chou, A.K.; et al. GSKIP- and GSK3-mediated anchoring strengthens cAMP/PKA/Drp1 axis signaling in the regulation of mitochondrial elongation. Biochim. Biophys. Acta 2015, 1853, 1796-1807. [CrossRef]

8. Dema, A.; Schroter, M.F.; Perets, E.; Skroblin, P.; Moutty, M.C.; Deak, V.A.; Birchmeier, W.; Klussmann, E. The A-Kinase Anchoring Protein (AKAP) Glycogen Synthase Kinase 3beta Interaction Protein (GSKIP) Regulates $\beta$-Catenin through Its Interactions with Both Protein Kinase A (PKA) and GSK3beta. J. Biol. Chem. 2016, 291, 19618-19630. [CrossRef]

9. Chou, C.H.; Yang, M.C.; Hsiao, B.X.; Wang, Y.H.; Liu, H.F.; Chiou, S.J.; Chuang, Y.C.; Yang, C.N.; Lieu, A.S.; Loh, J.K.; et al. The origin of GSKIP, a multifaceted regulatory factor in the mammalian Wnt pathway. Biochim. Biophys. Acta Mol. Cell Res. 2018, 1865, 1046-1059. [CrossRef]

10. Deak, V.A.; Skroblin, P.; Dittmayer, C.; Knobeloch, K.P.; Bachmann, S.; Klussmann, E. The A-kinase Anchoring Protein GSKIP Regulates GSK3 $\beta$ Activity and Controls Palatal Shelf Fusion in Mice. J. Biol. Chem. 2016, 291, 681-690. [CrossRef]

11. Plo, I.; Bellanné-Chantelot, C.; Vainchenker, W. ATG2B and GSKIP: 2 new genes predisposing to myeloid malignancies. Mol. Cell. Oncol. 2015, 3, e1094564. [CrossRef] [PubMed]

12. Saliba, J.; Saint-Martin, C.; Di Stefano, A.; Lenglet, G.; Marty, C.; Keren, B.; Pasquier, F.; Valle, V.D.; Secardin, L.; Leroy, G.; et al. Germline duplication of ATG2B and GSKIP predisposes to familial myeloid malignancies. Nat. Genet. 2015, 47, 1131-1140. [CrossRef] [PubMed]

13. Vattulainen-Collanus, S.; Akinrinade, O.; Li, M.; Koskenvuo, M.; Li, C.G.; Rao, S.P.; de Jesus Perez, V.; Yuan, K.; Sawada, H.; Koskenvuo, J.W.; et al. Loss of PPAR $\gamma$ in endothelial cells leads to impaired angiogenesis. J. Cell Sci. 2016, 129, 693-705. [CrossRef] [PubMed]

14. Alzheimer's Association. 2016 Alzheimer's disease facts and figures. Alzheimer's Dement 2016, 12, 459-509. [CrossRef]

15. Wimo, A.; Guerchet, M.; Ali, G.-C.; Wu, Y.-T.; Prina, A.M.; Winblad, B.; Jönsson, L.; Liu, Z.; Prince, M. The worldwide costs of dementia 2015 and comparisons with 2010. Alzheimer's Dement 2017, 13, 1-7. [CrossRef] [PubMed]

16. Serrano-Pozo, A.; Frosch, M.P.; Masliah, E.; Hyman, B.T. Neuropathological alterations in Alzheimer disease. Cold Spring Harb. Perspect. Med. 2011, 1, a006189. [CrossRef]

17. Duan, A.R.; Jonasson, E.M.; Alberico, E.O.; Li, C.; Scripture, J.P.; Miller, R.A.; Alber, M.S.; Goodson, H.V. Interactions between Tau and Different Conformations of Tubulin: Implications for Tau Function and Mechanism. J. Mol. Biol. 2017, 429, 1424-1438. [CrossRef]

18. Pradeepkiran, J.A.; Reddy, P.H. Structure Based Design and Molecular Docking Studies for Phosphorylated Tau Inhibitors in Alzheimer's Disease. Cells 2019, 8, 260. [CrossRef]

19. Lei, P.; Ayton, S.; Bush, A.I.; Adlard, P.A. GSK-3 in Neurodegenerative Diseases. Int. J. Alzheimer's Dis. 2011, 2011, 189246. [CrossRef]

20. Hernandez, F.; Gomez de Barreda, E.; Fuster-Matanzo, A.; Lucas, J.J.; Avila, J. GSK3: A possible link between beta amyloid peptide and tau protein. Exp. Neurol. 2010, 223, 322-325. [CrossRef]

21. Jayapalan, S.; Natarajan, J. The role of CDK5 and GSK3B kinases in hyperphosphorylation of microtubule associated protein tau (MAPT) in Alzheimer's disease. Bioinformation 2013, 9, 1023-1030. [CrossRef] [PubMed]

22. Muyllaert, D.; Kremer, A.; Jaworski, T.; Borghgraef, P.; Devijver, H.; Croes, S.; Dewachter, I.; Van Leuven, F. Glycogen synthase kinase-3 $\beta$, or a link between amyloid and tau pathology? Genes Brain Behav. 2008, 7 (Suppl. 1), 57-66. [CrossRef] [PubMed]

23. Hardy, J. A hundred years of Alzheimer's disease research. Neuron 2006, 52, 3-13. [CrossRef] [PubMed]

24. Bi, C.; Bi, S.; Li, B. Processing of Mutant $\beta$-Amyloid Precursor Protein and the Clinicopathological Features of Familial Alzheimer's Disease. Aging Dis. 2019, 10, 383-403. [CrossRef] [PubMed] 
25. Chang, K.H.; Lee-Chen, G.J.; Huang, C.C.; Lin, J.L.; Chen, Y.J.; Wei, P.C.; Lo, Y.S.; Yao, C.F.; Kuo, M.W.; Chen, C.M. Modeling Alzheimer's Disease by Induced Pluripotent Stem Cells Carrying APP D678H Mutation. Mol. Neurobiol. 2019, 56, 3972-3983. [CrossRef]

26. Mungenast, A.E.; Siegert, S.; Tsai, L.H. Modeling Alzheimer's disease with human induced pluripotent stem (iPS) cells. Mol. Cell. Neurosci. 2016, 73, 13-31. [CrossRef]

27. Seward, M.E.; Swanson, E.; Norambuena, A.; Reimann, A.; Cochran, J.N.; Li, R.; Roberson, E.D.; Bloom, G.S. Amyloid-beta signals through tau to drive ectopic neuronal cell cycle re-entry in Alzheimer's disease. J. Cell Sci. 2013, 126, 1278-1286. [CrossRef]

28. Lin, Y.T.; Cheng, J.T.; Yao, Y.C.; Juo Lo, Y.K.; Lin, C.H.; Ger, L.P.; Lu, P.J. Increased total TAU but not amyloid- $\beta(42)$ in cerebrospinal fluid correlates with short-term memory impairment in Alzheimer's disease. J. Alzheimer's Dis. 2009, 18, 907-918. [CrossRef]

29. Banito, A.; Rashid, S.T.; Acosta, J.C.; Li, S.; Pereira, C.F.; Geti, I.; Pinho, S.; Silva, J.C.; Azuara, V.; Walsh, M.; et al. Senescence impairs successful reprogramming to pluripotent stem cells. Genes Dev. 2009, 23, 21349. [CrossRef]

30. Huang, H.P.; Chen, P.H.; Hwu, W.L.; Chuang, C.Y.; Chien, Y.H.; Stone, L.; Chien, C.L.; Li, L.T.; Chiang, S.C.; Chen, H.F.; et al. Human Pompe disease-induced pluripotent stem cells for pathogenesis modeling, drug testing and disease marker identification. Hum. Mol. Genet. 2011, 20, 4851-4864. [CrossRef]

31. Chu, C.W.; Ko, H.J.; Chou, C.H.; Cheng, T.S.; Cheng, H.W.; Liang, Y.H.; Lai, Y.L.; Lin, C.Y.; Wang, C.; Loh, J.K.; et al. Thioridazine Enhances P62-Mediated Autophagy and Apoptosis Through Wnt/beta-Catenin Signaling Pathway in Glioma Cells. Int. J. Mol. Sci. 2019, 20, 473. [CrossRef] [PubMed]

32. Liu, F.; Liang, Z.; Wegiel, J.; Hwang, Y.W.; Iqbal, K.; Grundke-Iqbal, I.; Ramakrishna, N.; Gong, C.X. Overexpression of Dyrk1A contributes to neurofibrillary degeneration in Down syndrome. FASEB J. Off. Publ. Fed. Am. Soc. Exp. Biol. 2008, 22, 322433. [CrossRef] [PubMed]

33. Zhu, B.; Zhang, L.; Creighton, J.; Alexeyev, M.; Strada, S.J.; Stevens, T. Protein kinase A phosphorylation of tau-serine 214 reorganizes microtubules and disrupts the endothelial cell barrier. Am. J. Physiol. Lung Cell Mol. Physiol. 2010, 299, L493L501. [CrossRef] [PubMed]

34. Oliveira, J.; Costa, M.; de Almeida, M.S.C.; da Cruz, E.S.O.A.B.; Henriques, A.G. Protein Phosphorylation is a Key Mechanism in Alzheimer's Disease. J. Alzheimer's Dis. 2017, 58, 953-978. [CrossRef]

35. Liu, F.; Liang, Z.; Shi, J.; Yin, D.; El-Akkad, E.; Grundke-Iqbal, I.; Iqbal, K.; Gong, C.X. PKA modulates GSK-3 $\beta$ - and cdk5-catalyzed phosphorylation of tau in site- and kinase-specific manners. FEBS Lett. 2006, 580, 6269-6274. [CrossRef]

36. Wang, J.Z.; Grundke-Iqbal, I.; Iqbal, K. Kinases and phosphatases and tau sites involved in Alzheimer neurofibrillary degeneration. Eur. J. Neurosci. 2007, 25, 59-68. [CrossRef]

37. Chen, W.T.; Hong, C.J.; Lin, Y.T.; Chang, W.H.; Huang, H.T.; Liao, J.Y.; Chang, Y.J.; Hsieh, Y.F.; Cheng, C.Y.; Liu, H.C.; et al. Amyloid-beta (Abeta) D7H mutation increases oligomeric Abeta42 and alters properties of Abetazinc/copper assemblies. PLoS ONE 2012, 7, e35807.

38. Simic, G.; Babic Leko, M.; Wray, S.; Harrington, C.; Delalle, I.; Jovanov-Milosevic, N.; Bazadona, D.; Buee, L.; de Silva, R.; Di Giovanni, G.; et al. Tau Protein Hyperphosphorylation and Aggregation in Alzheimer's Disease and Other Tauopathies, and Possible Neuroprotective Strategies. Biomolecules 2016, 6, 6. [CrossRef]

39. Lan, M.Y.; Liu, J.S.; Wu, Y.S.; Peng, C.H.; Chang, Y.Y. A novel APP mutation (D678H) in a Taiwanese patient exhibiting dementia and cerebral microvasculopathy. J. Clin. Neurosci. 2014, 21, 513-515. [CrossRef]

40. Lin, Y.C.; Wang, J.Y.; Wang, K.C.; Liao, J.Y.; Cheng, I.H. Differential regulation of amyloid precursor protein sorting with pathological mutations results in a distinct effect on amyloid-beta production. J. Neurochem. 2014, 131, 407-412. [CrossRef]

41. Lee, S.Y.; Chiu, Y.J.; Yang, S.M.; Chen, C.M.; Huang, C.C.; Lee-Chen, G.J.; Lin, W.; Chang, K.H. Novel synthetic chalcone-coumarin hybrid for A $\beta$ aggregation reduction. CNS Neurosci. Ther. 2018, 24, 1286-1298. [CrossRef] [PubMed]

42. Safieh, M.; Korczyn, A.D.; Michaelson, D.M. ApoE4: An emerging therapeutic target for Alzheimer's disease. BMC Med. 2019, 17, 64. [CrossRef] [PubMed]

43. Lanoiselee, H.M.; Nicolas, G.; Wallon, D.; Rovelet-Lecrux, A.; Lacour, M.; Rousseau, S.; Richard, A.C.; Pasquier, F.; Rollin-Sillaire, A.; Martinaud, O.; et al. APP, PSEN1, and PSEN2 mutations in early-onset Alzheimer disease: A genetic screening study of familial and sporadic cases. PLoS Med. 2017, 14, e1002270. [CrossRef] [PubMed] 
44. Yu, Y.; Run, X.; Liang, Z.; Li, Y.; Liu, F.; Liu, Y.; Iqbal, K.; Grundke-Iqbal, I.; Gong, C.X. Developmental regulation of tau phosphorylation, tau kinases, and tau phosphatases. J. Neurochem. 2009, 108, 1480-1494. [CrossRef]

45. Sergeant, N.; Bretteville, A.; Hamdane, M.; Caillet-Boudin, M.L.; Grognet, P.; Bombois, S.; Blum, D.; Delacourte, A.; Pasquier, F.; Vanmechelen, E.; et al. Biochemistry of Tau in Alzheimer's disease and related neurological disorders. Expert Rev. Proteom. 2008, 5, 207-224. [CrossRef]

46. Hanger, D.P.; Anderton, B.H.; Noble, W. Tau phosphorylation: The therapeutic challenge for neurodegenerative disease. Trends Mol. Med. 2009, 15, 112-119. [CrossRef]

47. Martin, L.; Latypova, X.; Wilson, C.M.; Magnaudeix, A.; Perrin, M.L.; Yardin, C.; Terro, F. Tau protein kinases: Involvement in Alzheimer's disease. Ageing Res. Rev. 2013, 12, 289-309. [CrossRef]

48. Jeganathan, S.; von Bergen, M.; Mandelkow, E.M.; Mandelkow, E. The natively unfolded character of tau and its aggregation to Alzheimer-like paired helical filaments. Biochemistry 2008, 47, 10526-10539. [CrossRef]

49. Avila, J.; Jiménez, J.S.; Sayas, C.L.; Bolós, M.; Zabala, J.C.; Rivas, G.; Hernández, F. Tau Structures. Front. Aging Neurosci. 2016, 8, 262. [CrossRef]

50. Blennow, K.; Vanmechelen, E.; Hampel, H. CSF total tau, Abeta42 and phosphorylated tau protein as biomarkers for Alzheimer's disease. Mol. Neurobiol. 2001, 24, 87-97. [CrossRef]

51. Hampel, H.; Teipel, S.J.; Fuchsberger, T.; Andreasen, N.; Wiltfang, J.; Otto, M.; Shen, Y.; Dodel, R.; Du, Y.; Farlow, M.; et al. Value of CSF beta-amyloid1-42 and tau as predictors of Alzheimer's disease in patients with mild cognitive impairment. Mol. Psychiatry 2004, 9, 705-710. [CrossRef] [PubMed]

52. Mondragon-Rodriguez, S.; Basurto-Islas, G.; Santa-Maria, I.; Mena, R.; Binder, L.I.; Avila, J.; Smith, M.A.; Perry, G.; Garcia-Sierra, F. Cleavage and conformational changes of tau protein follow phosphorylation during Alzheimer's disease. Int. J. Exp. Pathol. 2008, 89, 81-90. [CrossRef] [PubMed]

53. Mondragón-Rodríguez, S.; Basurto-Islas, G.; Lee, H.-G.; Perry, G.; Zhu, X.; Castellani, R.J.; Smith, M.A. Causes versus effects: The increasing complexities of Alzheimer's disease pathogenesis. Expert Rev. Neurother. 2010, 10, 683-691. [CrossRef]

54. Wills, J.; Jones, J.; Haggerty, T.; Duka, V.; Joyce, J.N.; Sidhu, A. Elevated tauopathy and alpha-synuclein pathology in postmortem Parkinson's disease brains with and without dementia. Exp. Neurol. 2010, 225, 210-218. [CrossRef]

55. Carlyle, B.C.; Nairn, A.C.; Wang, M.; Yang, Y.; Jin, L.E.; Simen, A.A.; Ramos, B.P.; Bordner, K.A.; Craft, G.E.; Davies, P.; et al. cAMP-PKA phosphorylation of tau confers risk for degeneration in aging association cortex. Proc. Natl. Acad. Sci. USA 2014, 111, 5036-5041. [CrossRef] [PubMed]

56. Hu, Y.Y.; He, S.S.; Wang, X.; Duan, Q.H.; Grundke-Iqbal, I.; Iqbal, K.; Wang, J. Levels of nonphosphorylated and phosphorylated tau in cerebrospinal fluid of Alzheimer's disease patients: An ultrasensitive bienzyme-substrate-recycle enzyme linked immunosorbent assay. Am. J. Pathol. 2002, 160, 1269-1278. [CrossRef]

57. O’Brien, R.J.; Wong, P.C. Amyloid precursor protein processing and Alzheimer's disease. Annu. Rev. Neurosci. 2011, 34, 185-204. [CrossRef]

(C) 2019 by the authors. Licensee MDPI, Basel, Switzerland. This article is an open access article distributed under the terms and conditions of the Creative Commons Attribution (CC BY) license (http://creativecommons.org/licenses/by/4.0/). 